\title{
The Effectiveness of Carrot and Stick Incentive in Remuneration System of State Higher Education: an Experimental Research
}

\author{
Fajar Gustiawaty Dewi ${ }^{1}$, Susi Sarumpaet ${ }^{2}$, Rindu Rika Gamayuni ${ }^{3}$, Yunia Amelia ${ }^{4}$ \\ \{ fajargd@yahoo.com ${ }^{1}$, susi.sarumpaet@gmail.com ${ }^{2}$, rindu.gamayuni@yahoo.com ${ }^{3}$, \\ yuniaamelia@yahoo.com ${ }^{4}$ \}
}

Economic and Business Faculty, University of Lampung, Indonesia ${ }^{1,2,3,4}$

\begin{abstract}
In a remuneration system, employees who reach the specified performance targets will get performance incentives. Performance incentives that are applied can be carrot incentives (positive) or stick incentives (negative).Previous research on the effectiveness of carrots and stick incentives has not shown conclusive results. This study aims to provide evidence on the context of state universities in Indonesia. This research was conducted using experimental methods by the post-test only design and the University of Lampung lecturer as an experimental subject. Time-planning decision data as the dependent variable in the two incentive groups were tested using the Independent Sample T-Test. The study results showed that there are no differences in the time allocation decisions when given Carrot incentives and Stick incentives. However, this research provides evidence that lecturers are motivated to do all task: teaching, research, community service. These results recommended that the performance incentives is effective in encouraging lecturer performance.
\end{abstract}

Keywords: remuneration, carrot and stick, experiments, universities

\section{Introduction}

Evaluating the performance of public organizations is now increasingly important, including the area of education. The emergence of many rankings and leagues for world universities and colleges indicates that attention to the world of education has increased. Improvements in governance in tertiary institutions need to carry out on human resources, institutions, student affairs, research and community service, and innovation. Individual performance produced institutional performance, both lecturers and educational staff in it. Performance can be motivated through incentives. Organizations use incentives to motivate their employees to be more productive[1]. The remuneration system is expected to encourage individual performance. University management must begive more attention to salary satisfaction and employee's reward to increase employee performance motivation [2].The aim of this study was to examine the effectiveness of providing incentives in improving the performance of lecturers in higher educations.

\subsection{The Relation of Incentive and Performance}

[3] also state a significant relationship between financial compensation and employee career development. However, in the previous research shows that a reward and remuneration has a positive and significant psychological influence on job satisfaction, but does not 
significantly influence employee performance in private agencies[4]. Likewise, the remuneration incentive system policy has not significant effect on employees' performance in the tax office[5]. That research shows the inconsistency of the results of a previous study related to remuneration. Currently in Indonesia there are universities that apply positive incentives (carrot) and some are applying negative incentives (stick). However, there is no empirical evidence that shows that either of the two incentive models is more powerful in improving performance.

\subsection{Empirical Evidence About Carrot and Stick Incentives}

[6] using survey methods, show that managerial leadership styles that use the carrot and stick incentives are positively significant related to employee job satisfaction. [7]also indicates that performance appraisal and compensation systems (pay for performance) motivate lecturers. Different results from the research of [8] show that incentive compensation does not affect performance. Penalty contracts result in higher employee productivity compared to employee productivity using performance-based bonus contracts[1]. In contrast, the results of research by [9] show different results. His research shows that giving real positive incentives (carrot) is more efficient than awarding a joint carrot and stick incentive contract.

\section{Literature Review}

Expectancy Theory states that a person's motivation leads to an action that depends on the power of hope (Vroom, 1964 in [10]). The effect followed by specific results and depends on the results for the person. Expectancy theory argues that employees determine what behavior carried out and the value obtained for that behavior.

The performance measurement system had a significant positive impact on performance, but remuneration did not affect performance. Also, organizational culture can moderate the relationship between performance measurement systems on employee performance. On the other hand, corporate culture can strengthen the bond between remuneration and employee performance[5].

[3]provides evidence that there is a significant relationship between financial compensation and perceived career development with self-actualization. There is an inverse relationship between actual employees, monetary compensation, and career development. In line with that, [2] explained that employee salaries' satisfaction must be an absolute concern for University management to increase employee performance motivation. Civil servants' perception towards the remuneration system seen from the dimensions of transparency, fairness, control, and proportionality that tested for their effects on motivation and performance. Their study showed that transparency affects work motivation, but clarity does not affect employee work motivation. Other results show that proportion affects employees motivation employees, but balance does not affect lecturers motivation. While justice and control affect motivation, and motivation affect performance[11].

\subsection{Time-planning Decision}

Someone's seriousness about a job can be seen from the amount of time allocated to it. [12] show that managers change their time allocation with more in the area of financial and non-financial performance monitored or reported. The results of their research also provide 
evidence that performance-based incentives change managers' plans to allocate time. When incentives related to achieving goals in all areas, managers allocate more time to non-financial areas than financial areas.

Experimental research in the area of management control systems shows that there is a bonus role in increasing managerial efforts to achieve goals ([13]. Some further studies show that sometimes managers use effort to get bonuses, even if it has done in a way contrary to the overall organizational goals[14]). In general, these results indicate that the increase in the amount of information is progress towards increasing managerial efforts to achieve goals [14].Kershaw and Harrell (1999) use similar time planning measurements. Naylor \&Ilgen (1984) argues that the amount of time a person has to reach a goal shows the strength or level of one's commitment to the goal to be achieved, is a measure of one's efforts. [15]show that individuals who plan to devote more time to specific activities and after that will provide more time for those activities.

\subsection{Carrot Incentives and Stick Incentives}

The [1]show that negative incentives (sticks) will provide a stronger incentive to work better. Penalty contracts result in higher employee productivity compared to employee productivity using performance-based bonus contracts. Hannan et al. (2005) study in [1]conducted in the United States (US), Burkina Faso (Africa), Canada, and China show that penalty contracts motivate employees to perform more. This study indicates that negative incentives can motivate individuals more. Therefore, the hypothesis one in this study is : "Lecturers will allocate more time in carrying out the Tri Dharma of Higher Education when a negative incentive (stick) is applied than when a positive incentive (carrot) is applied".

A lecturer has the main task of carrying out the Tri Dharma of Higher Education, namely: Education and Teaching, Research, and Community Service plus supporting activities. A comprehensive control system aims to influence individual performance in all areas (Simon, 1995). Therefore the second hypothesis in this study is : "Lecturers will allocate more time in implementing Higher Education Tri Dharma for the entire assignment area when they get stick (negative) incentives than when they receive carrot (positive) incentives".

\section{Research Method}

\subsection{Subject Experiment}

This studyused a field experiment conducted at the Faculty of Economics and Business, Lampung University. The subject of the experiment was 30 lecturer from Lampung University.Control carry out on variables inherent in the subject, such as age, gender, education level, through random assignments, which are then tested by the chi-square test. Randomization in a simple way but essence gives the subject the same opportunity in receiving treatment.

The experimental subjects were then asked to decide how much allocation to carry out the duties of the Higher Education Tridharma each week. Data plan of lecturer working hours allocation were analyzed using independent sample T-test.

\subsection{Research Variable}


The independent variable in this research is incentives. Incentives are rewards given for performance achievements. [16] explain that the value of incentives becomes a crucial motivational construct defined as the value of a positive effect that is linked to approaching something and a negative impact with a tendency to avoid it. That way, incentives can be divided into two types, positive and negative. [17]states that positive incentives are gain, while the result of negative incentives is a loss.

The dependent variable in this research is time-planning decisions. [12] use timeplanning decisions to measure individual efforts' strength in achieving goals. The amount of time a person has to reach a goal shows the depth or level of one's commitment to the goal to be achieved, is a measure of one's efforts. Individuals will plan to devote more time to specific activities, and after that will carry them out[15]. The performance of lecturers is measured by the achievement of the Tridharma Higher Education performance targets, namely teaching, research, and service, preceded by the determination of the Employee Performance Targets and Lecturer Workload. This study's time planning decision was measured by the number of hours per week determined by the lecturer in carrying out the Higher Education Tri Dharma.

\subsection{Experimental Design}

The subjects were randomly divided into two groups. While the experimental design used was a post-test only design between subjects to test the two groups that received different treatments, namely:

- Group A received positive incentive (carrot) treatment

Subjects were given information about the awards given to each performance point that could be achieved by the lecturer. Then the subjects were asked to fill in the target work performance according to their abilities. Subjects were told that each achievement of the performance target would increase the amount of incentive rupiah to be received, but the amount was not yet known. Finally, the subject was asked to decide on the allocation of time plans given for each predetermined performance area.

- Group B received negative incentive (stick)teratment

Subjects were given information about the awards given to each performance point that could be achieved by the lecturer. Participants were asked to fill job performance targets according to their abilities. The subject was told that each achievement of the performance target would increase the incentive rupiah he would receive. Any performance target that is not achieved will reduce the number of incentives that were calculated earlier. Subjects can see firsthand the amount of rupiah that will be received to make its own set of performance targets. Finally, subjects were asked to decide on the allocation of time plans given for each predetermined performance area.

\section{Result \& Discussion}

The result of manipulation check shows that six people (20\%) of the experimental subjects did not pass the manipulation check so data that can be processed amounted to 24 people (80\%). However, this percentage still shows a reasonable number so that data processing can be continued.The experimental subjects' data are male as ten people $(42 \%)$, while the experimental female subjects are as many as 14 people (58\%).

The experimental subjects were randomly assigned 2 (two) conditions of manipulation. Table 3 shows descriptive statistics based on experimental conditions. In this 
study, the Chi-Square test variables of gender, age, education, and experience were controlled. Testing using Chi-Square Tests ( $\mathrm{df}=4 ; \mathrm{n}=24$ ) shows that there is no significant difference in the lecturer's time allocation plan in implementing Tri Dharma Higher Education for gender (Pearson $\chi^{2}=2.334 ; \mathrm{p}>0.310$ ), experience (Pearson $\chi^{2}=28.595 ; \mathrm{p}>0.433$ ), and education (Pearson $\chi^{2}=1.188 ; \mathrm{p}>0.552$ ), and age (Pearson $\left.\chi^{2}=41.179 ; \mathrm{p}>0.084\right)$.

Table 1 presents the mean of the time allocation decision per week for carrot (positive) and stick (negative) incentive types. The mean value of lecturer time allocation plan in carrying out all jobs to the Carrot type is 29.5 hours per week. As for the type of Stick incentive, the mean value of the lecturer time allocation plan in carrying out all jobs is 26.36 hours per week. From these results it can be seen that lecturers will allocate more time in carrying out the Higher Education Tri Dharma when negative incentives (sticks) are applied than when positive incentives (carrots) are applied. Homogeneity of variances test results show a significance value of 0,000 , which means that the data is homogeneous.

Table 1. Descriptive Statistic of Time Allocation Decision

\begin{tabular}{llcll}
\hline Incentive & $\mathbf{N}$ & Mean & DeviationStd & StdError \\
\hline CARROT & 13 & 29,15 & 4,160 & 1,154 \\
\hline STICK & 11 & 26,36 & 2,803 & 0,845 \\
\hline
\end{tabular}

Table 2. Independent Sample T-Test Time of Allocation Decision for Incentive Types

\begin{tabular}{c|c|c|c|}
\hline MeanDifference & F & Sig & Conclusion \\
\hline 2,790 & 6,40 & 0,064 & $\begin{array}{c}\text { H1 is not } \\
\text { supported }\end{array}$ \\
\hline
\end{tabular}

Table 2 shows no significant difference between the mean value of lecturer time allocation plans in the Carrot incentive type and the Stick incentive type (p-value> 0.05). Thus H1 is not supported. This result indicates that a lecturer has not responded to the incentive type provided, with Carrot (positive) and Stick (negative) in doing the Higher Education Tri Dharma. This result is not consistent with the research result by Nosenzo (2016), which shows that negative incentives will provide a stronger impetus to work better. Penalty contracts result in higher employee productivity compared to employee productivity using performance-based bonus contracts.

Table 3. Descriptive Statistic of Job Area

\begin{tabular}{lllllc}
\hline Area & $\mathbf{N}$ & Mean & DeviationStd & StdError \\
\hline All & 6 & 33 & 2,449 & 1,000 \\
\hline Partial & & 1 & 26,17 & 2,333 & 0,550 \\
& 8 & & & & \\
\hline
\end{tabular}

Table 3 shows that the mean of time allocation plan for all types of incentives is 33 hours per week to implement all job areas of the Higher Education Tri Dharma. While the mean of the time allocation plan for all types of incentives, both Carrot and Stick, is 26.17 hours per week to carry out only part of the job area. This result means that by giving performance incentives, both using the Carrot and Stick types responded positively by lecturers to carry out the Higher Education Tri Dharma tasks.

Table 4. Independent Sample T-Test of Time Allocation Decision for Job Area

\begin{tabular}{l|l|l|l} 
MeanDifference & F & Sig & Conclusion
\end{tabular}




\begin{tabular}{|l|l|l|l|}
\hline 6,833 & 0,001 & 0,000 & $\mathrm{H} 2$ is supported
\end{tabular}

From the table 4 it can be seen that there is a significant difference between the mean value of the lecturer time allocation plan in implementing Higher Education's Tri Dharma in all types of performance incentives. Lecturers are more motivated to carry out all job areas compared to only in part of the job area. Thus, $\mathrm{H} 2$ is supported. This indicates that a lecturer will carry out the entire assignment area, namely: Education and teaching, research, community service, and supporting activities if given incentives for performance achievements.

The results of this study are in line with the results of research by [12] conducted at manufacturing companies. In his research [12] show that managers change their time allocation with more in the area of financial and non-financial performance that is monitored or reported. The results of their research also provide evidence that performance-based incentives change managers' plans to allocate time.

\section{Conclusion}

The results of this study cannot provide evidence that by applying stick (negative) incentives, the lecturer apparently plans to spend more time to carry out their tasks because the amount of performance incentives to be received can be known upfront. There is no difference in lecturer time allocation plans when given Carrot incentives and Stick incentives. Nevertheless, this study provides evidence that lecturers are more motivated to carry out all job areas than only in a part of the job area. This result indicates that a lecturer will carry out the entire job area: Education and teaching, research, community service, and supporting activities if given incentives for performance achievements. These results are consistent with the Expectancy Theory.

This research suggested recommendations for the higher education institution in choosing a remuneration system that will be applied. The provision of performance incentives in remuneration has the objective to encourage the motivation of lecturers to get more leverage in carrying out their tasks. Next research is suggested to increase the number of experimental subjects, and also be conducted at different universities.

\section{References}

[1] D. Nosenzo, "Employee incentives: Bonuses or penalties?," IZA World Labor, Jan. 2016, doi: 10.15185/izawol.234.

[2] R. Olawale and I. Olanrewaju, "Investigating The Influence Of Financial Reward On Lagos State University Staff Turnover Intention,” Eur. Sci. Journal, ESJ, vol. 12, no. 10, p. 161, 2016, doi: 10.19044/esj.2016.v12n10p161.

[3] S. Ghafoor, N. Ansari, and A. Moazzam, "The Effect of Financial Compensation and Perceived Career Progression on Employee Turnover Intentions with Self Actualization as a Mediator," Gov. Manag. Rev., vol. 1, no. 2, pp. 67-91, 2017.

[4] R. N.-U.-D. Jalal and M. A. Zaheer, "Does Job Satisfaction Mediate the Relationship of Workload, Remuneration and Psychological Reward with Job Performance?," Int. J. Acad. Res. Bus. Soc. Sci., vol. 7, no. 9, 2017, doi: 10.6007/ijarbss/v7-i9/3309.

[5] D. N. F. Rokhimakhumullah, "the Effect of Performance Measurement System and Remuneration To Employee Performance With Organizational Culture As a Moderating 
Variable,” J. Innov. Bus. Econ., vol. 1, no. 02, p. 93, 2017, doi: 10.22219/jibe.vol1.no02.93100 .

[6] K. Dartey-Baah and E. Ampofo, “'Carrot and stick' leadership style: Can it predict employees' job satisfaction in a contemporary business organisation?," African J. Econ. Manag. Stud., vol. 7, no. 3, pp. 328-345, 2016, doi: 10.1108/AJEMS-04-2014-0029.

[7] K. Türk, "Performance appraisal and the compensation of academic staff in the University of Tartu," Balt. J. Manag., vol. 3, no. 1, pp. 40-54, 2008, doi: 10.1108/17465260810844257.

[8] T. Iaffaldano, Michelle and M. Michinsky, Paul, "Job satisfaction and job performance: a metaanalysis," Psychol. Bull., vol. 97, no. 2, pp. 1689-1699, 1983, doi: 10.1017/CBO9781107415324.004.

[9] E. Fehr and K. M. Schmidt, "Adding a stick to the carrot? the interaction of bonuses and fines," Am. Econ. Rev., vol. 97, no. 2, pp. 177-181, 2007, doi: 10.1257/aer.97.2.177.

[10] R. M. Steers, R. T. Mowday, and D. L. Shapiro, "Introduction to Special Topic Forum: The Future of Work Motivation Theory," Acad. Manag. Rev., vol. 29, no. 3, p. 379, 2004, doi: $10.2307 / 20159049$.

[11] S. N. Jayakusuma, S. Sarumpaet, and F. G. Dewi, "The perception of civil servants in higher education to remuneration system, and its effect on motivation and performance," Int. J. Sci. Technol. Res., vol. 7, no. 9, pp. 129-137, 2018.

[12] M. J. U. and B. M. Tuttle, "The Effects of Comprehensive Information Reporting Systems and Economic Incentives on Managers' Time-Planning Decisions," Behav. Res. Account., vol. 16, pp. 89-105, 2004.

[13] S. E. Bonner and G. B. Sprinkle, "The effects of monetary incentives on effort and task performance: Theories, evidence, and a framework for research," Accounting, Organ. Soc., vol. 27, no. 4-5, pp. 303-345, 2002, doi: 10.1016/S0361-3682(01)00052-6.

[14] A. Harrell and P. Harrison, "An incentive to shirk, privately held information, and managers' project evaluation decisions," Accounting, Organ. Soc., vol. 19, no. 7, pp. 569-577, 1994, doi: 10.1016/0361-3682(94)90024-8.

[15] M. and B. Mc. Allister, "The contingency model for the selection of decision strategies: an empirical test," Univ. Washingt., 1979.

[16] D. Wicker, Frank W., and Hamman, "Goal orientation, goal difficulty, and incentive values of academic goals," Psychol. Rep., vol. 96, pp. 681-689, 2005.

[17] K. Sassenberg, K. J. Jonas, J. Y. Shah, and P. C. Brazy, "Why some groups just feel better: The regulatory fit of group power," J. Pers. Soc. Psychol., vol. 92, no. 2, pp. 249-267, 2007, doi: 10.1037/0022-3514.92.2.249. 